\title{
Comparison of Intravenous Lipid Emulsion, Bicarbonate, and Glucagon Treatments in a Rabbit Model of Clomipramine Toxicity
}

\author{
Hasan Kara ${ }^{1, \star}$, Ayşegül Bayir ${ }^{1}$, Ahmet Ak ${ }^{1}$, Ali Ünlü ${ }^{2}$, \\ Seyit Ali Kayis ${ }^{3}$
}

\author{
${ }^{1}$ Selçuk University, Faculty of Medicine, \\ Department of Emergency Medicine, \\ Konya, Turkey \\ ${ }^{2}$ Selçuk University, Faculty of Medicine, \\ Department of Biochemistry, Konya, \\ Turkey \\ ${ }^{3}$ Karabuk University, Faculty of \\ Medicine, Department of Medical \\ Informatics, Karabuk, Turkey

\section{*Correspondence} \\ hasankara42@gmail.com (Hasan Kara) \\ Funding information \\ Selçuk Üniversitesi Bilimsel Araştırma \\ Projeleri Koordinatörlüğü
}

\begin{abstract}
Background: This experimental study aimed to evaluate intravenous lipid emulsion, sodium bicarbonate, and glucagon as treatment options for the cardiotoxicity associated with clomipramine, a tricyclic antidepressant, and the antidotal effects of these drugs. Methods: In this experimental study, female and male New Zealand rabbits were divided into a sham group, a sodium bicarbonate treatment group, an intravenous lipid emulsion treatment group, and a glucagon treatment group. After the administration of a single dose of oral clomipramine $(70 \mathrm{mg} / \mathrm{kg})$, through an orogastric tube, vital parameters such as mean arterial pressure and oxygen saturation were measured, using a bedside monitor. Intoxication was established after the mean arterial pressure decreased to $40 \%-45 \%$, within approximately $30-45$ minutes. Treatments were administered after intoxication was established. Results: Although the mean arterial pressure values significantly changed over time in the sham and glucagon treatment groups, no significant changes were observed in the intravenous lipid emulsion and sodium bicarbonate treatment groups. Significant differences were observed among the values at 0 min compared with 30,60 , and 120 min in both the sham and the glucagon treatment groups. The clomipramine level changed significantly in all groups. Conclusion: Tricyclic antidepressant poisoning remains a difficult therapeutic challenge. Glucagon, a lipophilic drug, appears to be a promising candidate for the treatment of clomipramine-induced cardiotoxicity and should be considered early for the treatment of severe tricyclic antidepressant overdose.
\end{abstract}

\section{Keywords}

TCA intoxication, Glucagon, Sodium bicarbonate, Intravenous lipid emulsion, Antidotes

\section{Introduction}

Tricyclic antidepressants (TCAs) were first approved by the Food and Drug Administration for antidepressant treatment in the 1950s. TCAs have been used extensively for the management of depression and other psychiatric disorders. Traditional TCAs include imipramine, desipramine, amitriptyline, nortriptyline, doxepin, trimipramine, protriptyline, and clomipramine [1]. Clomipramine is a frequently prescribed TCA because it is inexpensive.
Clomipramine is metabolized by cytochrome $\mathrm{P} 450$ (CYP 450 2D6), in the liver, and is further metabolized into desmethyl clomipramine, a stable, active metabolite, by CYP 450 1A2. Although clomipramine affects serotonin uptake, the active metabolite affects norepinephrine uptake [2]. The half-life of clomipramine is 17-28 hours, and its cardiotoxic effects begin to emerge approximately 30 minutes after overdose intake, although its plasma peak time is $2-6$ hours at therapeutic doses. The total therapeutic range of clomipramine is $230-450 \mathrm{ng} / \mathrm{ml}$, and it becomes 
T A B L E 1. Properties of different treatments at different time points. Values are expressed as the median (min-max).

\begin{tabular}{|c|c|c|c|c|c|c|}
\hline Traits & Time (min) & Sham & ILE & Glucagon & $\mathrm{NaHCO3}$ & p1 \\
\hline MAP & 0 & $90.5(59.0-95.0)^{A B, a}$ & $83.5(72.0-100.0){ }^{A B}$ & $96.5(92.0-98.0)^{A, a}$ & $85.0(40.0-89.0)^{B}$ & 0.020 \\
\hline \multirow[t]{3}{*}{ (mmHg) } & 30 & $76.5(58.0-92.0)^{a b}$ & $69.5(55.0-81.0)$ & $61.0(44.0-65.0)^{b}$ & $77.0(58.0-78.0)$ & 0.102 \\
\hline & 60 & $84.5(46.0-94.0)^{a b}$ & $72.0(50.0-88.0)$ & $62.0(55.0-80.0)^{b}$ & $75.0(63.0-89.0)$ & 0.322 \\
\hline & 120 & $63.5(43.0-76.0)^{b}$ & $69.0(57.0-97.0)$ & $72.0(57.0-83.0)^{b}$ & $84.0(73.0-95.0)$ & 0.080 \\
\hline \multirow[t]{2}{*}{$\mathbf{P 2}$} & & 0.003 & 0.172 & 0.002 & 0.266 & \\
\hline & 0 & $40.0(40.0-50.0)$ & $45.0(40.0-80.0)$ & $55.0(40.0-80)$ & $55.0(40.0-60.0)$ & 0.096 \\
\hline QRS & 30 & $50.0(40.0-60.0)$ & $50.0(50.0-80.0)$ & $55.0(40.0-100.0)$ & $50.0(50.0-60.0)$ & 0.704 \\
\hline duration & 60 & $55.0(40.0-70.0)$ & $60.0(50.0-80.0)$ & $60.0(50.0-100.0)$ & $55.0(50.0-60.0)$ & 0.602 \\
\hline (ms) & 120 & $60.0(40.0-80.0)$ & $60.0(50.0-80.0)$ & $55.0(40.0-80.0)$ & $60.0(50.0-130.0)$ & 0.932 \\
\hline $\mathbf{P 2}$ & & 0.021 & 0.275 & 0.065 & 0.154 & \\
\hline \multirow[t]{4}{*}{$\mathrm{SO}_{2}(\%)$} & 0 & $85.0(84.0-88.0)^{A}$ & $87.5(67.0-98.0)^{A}$ & $64.5(51.0-72.0)^{B, a}$ & $92.0(82.0-97.0)^{A}$ & 0.004 \\
\hline & 30 & $92.5(83.0-95.0)$ & $87.0(82.0-96.0)$ & $81.0(72.0-98.0)^{a b}$ & $90.0(80.0-95.0)$ & 0.308 \\
\hline & 60 & $88.5(82.0-99.0)$ & $84.0(64.0-100.0)$ & $92.0(92.0-97.0)^{b}$ & $91.0(89.0-97.0)$ & 0.535 \\
\hline & 120 & $89.0(75.0-99.0)$ & $82.5(68.0-96.0)$ & $86.0(85.0-90.0)^{b}$ & $81.0(80.0-90.0)$ & 0.317 \\
\hline P2 & & 0.249 & 0.642 & 0.003 & 0.145 & \\
\hline \multirow[t]{3}{*}{ pH } & 0 & $7.37(7.34-7.41)^{A, a}$ & $7.26(7.11-7.33)^{B}$ & $7.51(7.38-7.56)^{C}$ & $7.49(7.42-7.52)^{C}$ & 0.000 \\
\hline & 60 & $7.45(7.42-7.49)^{A, b}$ & $7.36(7.28-7.42)^{B}$ & $7.41(7.34-7.45)^{A B}$ & $7.40(7.39-7.47)^{A B}$ & 0.026 \\
\hline & 120 & $7.45(7.37-7.50) A B, b$ & $7.35(7.28-7.46)^{A}$ & $7.43(7.35-7.51)^{A B}$ & $7.49(7.46-7.56)^{B}$ & 0.015 \\
\hline $\mathbf{P 2}$ & & 0.005 & 0.042 & 0.067 & 0.091 & \\
\hline $\mathbf{p O}_{2}$ & 0 & $79.9(64.0-123.4)$ & $73.7(54.8-90.0)$ & $79.8(64.2-108.6)$ & $78.5(53.6-88.4)$ & 0.860 \\
\hline \multirow[t]{2}{*}{ (mmHg) } & 60 & $83.2(73.0-110.0)$ & $73.9(51.2-117.7)$ & $82.1(60.3-88.7)$ & $80.2(51.0-117.8)$ & 0.727 \\
\hline & 120 & $86.5(75.9-90.6)$ & $80.5(49.1-97.8)$ & $70.8(60.9-115.3)$ & $109.3(70.3-128.9)$ & 0.451 \\
\hline $\mathbf{P 2}$ & & 0.847 & 0.847 & 0.817 & 0.247 & \\
\hline $\mathbf{p C O}_{2}$ & 0 & $34.3(19.1-39.9)^{A}$ & $39.9(34.1-55.6)^{A B}$ & $43.4(37.7-44.8)^{B}$ & $41.3(37.2-45.7)^{B, a}$ & 0.033 \\
\hline \multirow[t]{2}{*}{ (mmHg) } & 60 & $26.6(25.7-38.6)$ & $37.8(21.4-51.4)$ & $35.3(32.3-39.0)$ & $33.4(20.7-48.3)^{a b}$ & 0.202 \\
\hline & 120 & $32.2(27.2-34.4)$ & $33.2(29.9-40.2)$ & $32.8(28.4-38.7)$ & $33.4(13.2-33.8)^{b}$ & 0.731 \\
\hline $\mathbf{P 2}$ & & 0.114 & 0.847 & 0.065 & 0.023 & \\
\hline $\mathrm{HCO}_{3}$ & 0 & $19.6(12.0-22.9)^{A}$ & $17.9(8.3-21.4)^{A}$ & $33.5(22.1-39.1)^{B}$ & $31.3(24.6-37.0)^{B}$ & 0.000 \\
\hline \multirow[t]{2}{*}{$(\mathbf{m E q} / \mathbf{L})$} & 60 & $19.2(17.2-27.7)$ & $19.9(10.6-33.5)$ & $21.1(20.4-24.4)$ & $20.0(13.3-32.6)$ & 0.319 \\
\hline & 120 & $21.6(17.0-23.8)$ & $17.9(15.8-25.5)$ & $22.5(16.3-25.6)$ & $24.2(10.1-29.8)$ & 0.328 \\
\hline $\mathbf{P 2}$ & & 0.311 & 0.847 & 0.065 & 0.091 & \\
\hline Clomipramine & 0 & $0.06(0.04-0.21)^{A, a}$ & $0.29(0.13-0.48)^{B C, a}$ & $1.85(0.29-11.10)^{B, a}$ & $0.10(0.02-0.46){ }^{A C, a}$ & 0.002 \\
\hline \multirow[t]{2}{*}{$(\mu \mathrm{g} / \mathrm{L})$} & 60 & $6.55(2.62-24.00)^{A B, b}$ & $33.2(6.70-158.00)^{C, b} 1$ & $11.25(6.06-37.00){ }^{A C, b}$ & $3.17(1.40-4.21)^{B, b}$ & 0.002 \\
\hline & 120 & $14.50(3.00-87.00)^{b}$ & $28.55(4.32-53.80)^{b}$ & $5.58(4.72-19.70)^{b}$ & $20.50(5.30-36.80)^{c}$ & 0.301 \\
\hline P2 & & 0.011 & 0.009 & 0.035 & 0.002 & \\
\hline
\end{tabular}

P1: $p$ values for each row obtained using Kruskall Wallis test. Statistically significant group(s) were determined via MannWhitney U test. Correction were made according to Benjamini, Y., and Hochberg, Y. (1995) due to multiple testing procedure [13]. Median do not share common superscript uppercase letter significantly differ from each other. $(p<0.05)$.

P2: $p$ values for each treatment for timewise comparison obtained using Friedman test. Statistically significant group(s) were determined using Wilcoxon Signed Rank Test. Correction were made according to Benjamini, Y., and Hochberg, Y. (1995) due to multiple testing procedure [13]. Median do not share common superscript lowercase letter significantly difer from each other $(p<0.05)$. 
toxic at doses above $450 \mathrm{ng} / \mathrm{ml}$. Although clomipramine binds to proteins at a rate of $97 \%-98 \%$, its bioavailability is only $50 \%$, with $60 \%$ being excreted in urine and $32 \%$ excreted in feces. Clomipramine has a large distribution volume because it is a lipophilic agent[3].

TCA intoxication has been associated with severe morbidity and mortality, rendering this issue highly important. TCAs block the alpha-adrenergic receptors and have anticholinergic effects. The blockade of fast sodium channels in myocardial cells can slow action potentials and provide a membrane-stabilizing effect, which can cause sinus tachycardia, cardiac conduction disorders, vasodilation, arrhythmias, hypotension, or asystole. The anticholinergic effects of TCAs include dry mouth, blurred vision, dilated pupils, hyperthermia, and delayed gastric emptying. Neurological symptoms associated with TCA use include numbness, coma, respiratory depression, seizures, and delirium $[4,5]$.

For the treatment of TCA overdose, favorable results have been reported among patients treated with gastrointestinal decontamination, activated charcoal administration, intravenous (IV) fluids, sodium bicarbonate $\left(\mathrm{NaHCO}_{3}\right)$ infusion, magnesium sulfate, vasopressors, glucagon, and intralipid infusion [5]. In response to TCA intoxication, IV $\mathrm{NaHCO}_{3}$ is commonly used to prevent ventricular arrhythmias and hypotension, to correct metabolic acidosis, and to promote the binding of TCAs to proteins, reducing free drug quantities. Epinephrine, norepinephrine, and dopamine may be administered if hypotension cannot be treated, despite IV fluid replacement. Benzodiazepines may also be added to the treatment to prevent seizures $[6,7]$.

Intravenous lipid emulsions (ILEs) have been widely used during the resuscitation of lipophilic drug overdoses associated with neurological and cardiotoxic effects and are recommended as life-saving treatments in cases of severe hemodynamic instability [5].

Glucagon, which has been used to treat TCA intoxication (as well as beta-blocker and calcium channel blocker intoxication), has been reported to be effective for the treatment of refractory hypotension or arrhythmias, through the stimulation of adenyl cyclase, which has positive inotropic and chronotropic effects, independent of adrenergic receptor activity, increasing the intracellular calcium levels in the myocardium and stimulating endogenous epinephrine release from the adrenal medulla[8, 9].

The present study aimed to investigate whether ILE, $\mathrm{NaHCO}_{3}$, or glucagon could be used as antidotes to rescue the hemodynamic and cardiac parameters following experimentally induced clomipramine intoxication.

\section{Materials and methods}

\subsection{Study Design}

This study investigated potential antidote treatments for clomipramine-induced cardiotoxicity. Throughout the experimental procedures, every effort was made to minimize animal suffering and the number of animals used. This experimental procedure was approved by the Institutional
Animal Care and Use Committee of Selçuk University. Both female and male New Zealand rabbits were used in this study. The animals were randomly divided into the following four groups, each containing six animals: the sham group, in which experimentally induced intoxication was performed, without treatment and the $\mathrm{NaHCO}_{3}$, ILE, and glucagon treatment groups.

Anesthesia was provided by administering $50 \mathrm{mg} / \mathrm{kg}$ ketamine and $4 \mathrm{mg} / \mathrm{kg}$ xylazine $\mathrm{HCl}$, via the intramuscular root in the hind leg of each rabbit, for all groups. The IV route was established using a $22 \mathrm{G}$ cannula in the dorsal ear vein, to obtain blood samples and administer fluids. The intoxication criterion was a $40 \%-45 \%$ reduction in the mean arterial pressure (MAP), relative to baseline values, within 30-45 min following the administration of $70 \mathrm{mg} / \mathrm{kg}$ clomipramine in a single dose, via the orogastric route. Vital parameters were measured using a bedside monitor. Electrocardiography (ECG) records were obtained at 0, 30, 60, and 120 mins, and MAPs were recorded. At 0,1 , and 2 hours, 5-ml blood samples were drawn and placed into gel tubes, to perform blood gas and plasma clomipramine measurements. For the sham group, ECG recordings were obtained at $0,30,60$, and 120 mins, after intoxication was established, and the rabbits were sacrificed with highdose ketamine after the final ECG recording was obtained $[10,11]$. In the $\mathrm{NaHCO}_{3}$ group, after intoxication was established, 8.4\% hypertonic $\mathrm{NaHCO}_{3}$ was administered $\mathrm{IV}$, at a loading dose of $4 \mathrm{ml} / \mathrm{kg}$ over $5 \mathrm{~min}$ and a maintenance dose of $4 \mathrm{ml} / \mathrm{kg} / \mathrm{h}$, until the test was terminated. In the ILE group, after intoxication was established, a lipid emulsion was administered as a $1.5 \mathrm{mg} / \mathrm{kg}$ bolus, followed by a $0.25 \mathrm{mg} / \mathrm{kg} / \mathrm{h}$ infusion rate. In the glucagon group, after intoxication was established, glucagon was administered as a $2 \mathrm{mg} / \mathrm{kg}$ bolus, followed by a $0.1 \mathrm{mg} / \mathrm{kg} / \mathrm{h}$ infusion rate. ECG recordings were performed at $0,30,60$, and 120 mins, and vital parameters were recorded. For all treatment groups, 5-ml blood samples were placed into gel tubes at 0 , 1 , and 2 hours, to determine venous blood gas and plasma clomipramine levels. The surviving rabbits were sacrificed with high-dose ketamine after the final 120-min samples and recordings were obtained.

\subsection{Biochemical Measurements}

Mass spectrometer (MS) analysis was performed using an ABSCIEX API 3200 triple quadrupole mass spectrometer (USA), Shimadzu LC-20-AD (Kyoto, Japan), with a positive mode electrospray ion (ESI) source. Data were analyzed using the ABSCIEX Analyst Software Wizard 1.6.1 program. The Phenomenex Luna C18 (5 $\mu \mathrm{m}, 4.6 \times$ $50 \mathrm{~mm}$ ) was used as the analytical column. The mobile phase consisted of water/methanol $(1 / 9, \mathrm{v} / \mathrm{v})$, containing $1 \%$ formic acid, using an isocratic pump. The analysis time was set to 10 minutes. A $200 \mu \mathrm{L}$ volume of an internal standard ( $1 \mu \mathrm{g} / \mathrm{ml}$ acetaminophen) was added to $200 \mu \mathrm{L}$ of plasma and vortexed for 20 seconds. After the addition of 3 $\mathrm{ml}$ ethyl acetate the mixture, vortexing was performed for an additional 5 minutes. After centrifugation, the organic 

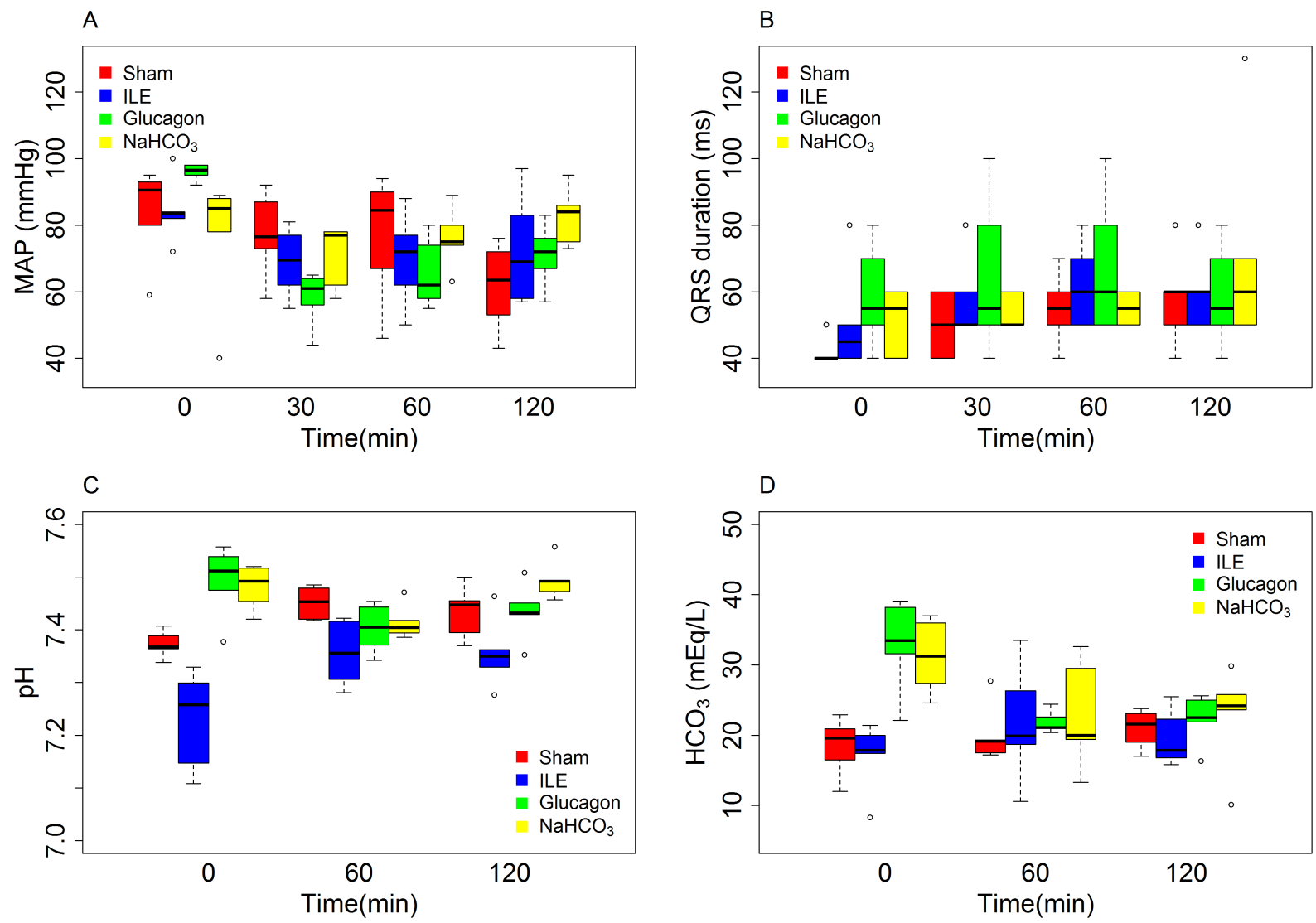

F IG U RE 1. Boxplot for the treatment groups at $0,30,60$, and 120 minutes showing. A) mean arterial pressure (MAP) and B) QRS. Boxplots for the treatment groups at 0, 60, and 120 minutes for C) $\mathrm{pH}$ and $\mathrm{D}) \mathrm{HCO}_{3}$.

layer was removed to a new tube and evaporated under nitrogen gas, at $40{ }^{\circ} \mathrm{C}$. The residue was vortexed for 30 seconds in $200 \mu \mathrm{L}$ methanol, and $10 \mu \mathrm{L}$ of each sample was injected into the liquid chromatography (LC)-tandem MS (MS/MS) device, for chromatography. The limit of detection (LOD) and limit of quantification (LOQ) levels for this method were 0.006 and $0.02 \mu \mathrm{g} / \mathrm{L}$ respectively. This method was linear in the range from $0.002-400 \mu \mathrm{g} / \mathrm{L}$.

\subsection{Statistical Analysis}

Descriptive statistics were obtained for the treatment groups. Before the statistical analysis, the AndersonDarling normality test was used to verify the normality of the data. All variables were not normally distributed, and transformations were not sufficient to stabilize the variance. Therefore, non-parametric tests were employed for data analysis. The Kruskal-Wallis test was used for multiple group comparisons, and the Mann-Whitney U test was employed for post hoc comparisons. The Friedman test was used to analyze repeated measures within groups, and the Wilcoxon Signed Rank Test was conducted for post hoc analyses. A p-value $<0.05$ was considered significant. All statistical analyses were performed using the R statistical package [12].

\section{Results}

The results for four experimental groups, sham, ILE, glucagon, and $\mathrm{NaHCO}_{3}$ treatment groups, were evaluated. One rabbit in the glucagon group and one rabbit in the $\mathrm{NaHCO}_{3}$ group died before completing the study. The median (min-max) values for MAP, QRS, $\mathrm{SO}_{2}, \mathrm{pH}, \mathrm{pO}_{2}$, $\mathrm{pCO}_{2}, \mathrm{HCO}_{3}$, and clomipramine variables are presented in Table 1. To facilitate visual comparison between groups at each time point and within subjects for the different time points of traits MAP, QRS, $\mathrm{pH}$, and $\mathrm{HCO}_{3}$ are provided in the Fig. 1 and in Fig. 2 for clomipramine, separately.

Although the MAP values changed significantly over time in the sham and glucagon treatment groups $(p=0.003$ and $p=0.002$, respectively), no significant changes were observed in the ILE and $\mathrm{NaHCO}_{3}$ treatment groups (Table 1). Significant differences were observed for the MAP values at 0 minutes compared with those at 30,60, and 120 minutes in both the sham and glucagon treatment groups (Fig. 1). Although the MAP values decreased significantly after the 0-minute time point in both groups, the QRS increased significantly only in the sham group (Fig. 1). $\mathrm{SO}_{2}$ values also changed significantly, increasing with time in the glucagon treatment group $(p=0.003$; Table 1$)$. Whereas the $\mathrm{pH}$ values changed significantly in the sham and ILE 
treatment groups, no significant differences were observed over time in either the glucagon or $\mathrm{NaHCO}_{3}$ treatment groups (Table 1). Significant decreases in the $\mathrm{pCO}_{2}$ values over time were only detected in the $\mathrm{NaHCO}_{3}$ treatment group ( $p=0.023)$. No significant changes were observed in any of the groups for $\mathrm{pO}_{2}$ and $\mathrm{HCO}_{3}$ values (Table 1 ). The clomipramine level changed significantly in all groups $(\mathrm{p}=$ $0.011, p=0.009, p=0.035$, and $p=0.002$ for the sham, ILE, glucagon, and $\mathrm{NaHCO}_{3}$ treatment groups, respectively). Although clomipramine levels increased across all time points in both the sham and $\mathrm{NaHCO}_{3}$ treatment groups, they began to decrease after 60 minutes in the ILE and glucagon treatment groups (Fig. 2).

Significant differences among groups were observed for MAP, $\mathrm{pCO}_{2}$, and $\mathrm{HCO}_{3}$ values at the 0 -minute time point ( $\mathrm{p}$ $=0.020, p=0.033$, and $\mathrm{p}<0.001$, respectively). Significant differences among groups were also observed for $\mathrm{pH}$ values at 0,60 , and 120 minutes $(\mathrm{p}<0.001, \mathrm{p}=0.026$, and $\mathrm{p}=$ 0.015 , respectively). Significant differences among groups were observed for clomipramine levels at 0 and 60 minutes $(\mathrm{p}=0.002$ and $\mathrm{p}=0.002$, respectively; Table 1$)$.

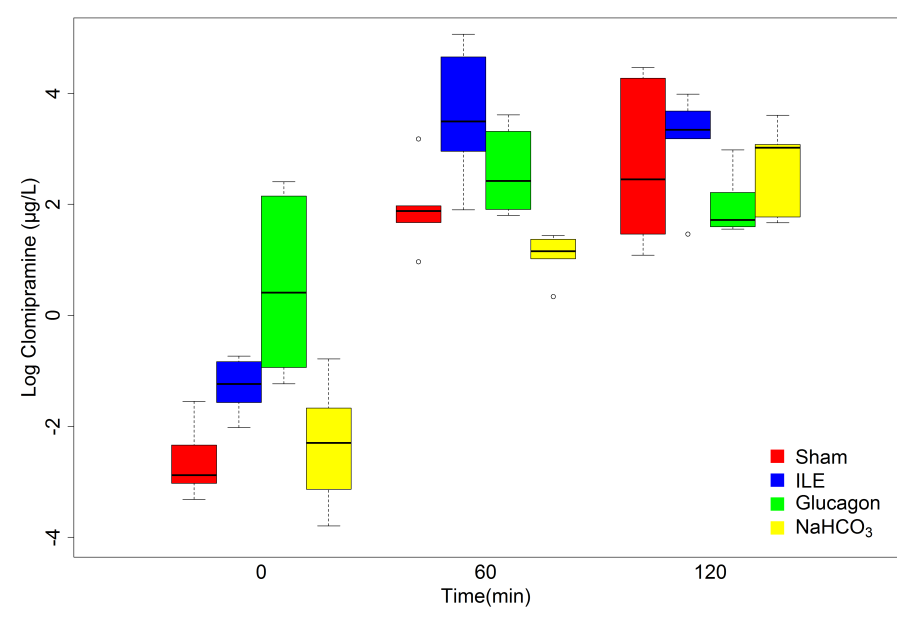

F I G URE 2. Boxplots for the treatment groups at 0 , 60, and 120 minutes for Log clomipramine. Note that Log is a monotonic function.

\section{Discussion}

Although the results of the present study suggest the potential that glucagon may be used as an antidote for clomipramine intoxication, better-designed and more comprehensive animal studies are required. The main limitations of the present study include difficulties in the management of orogastric clomipramine administration, caused by potential changes in gastric motility, technical restrictions for the monitoring and assessment of vital signs, and the insufficient assessment the acidosis influence on drug levels, due to the absence of a group in which glucagon treatment was applied together with $\mathrm{NaHCO}_{3}$ or ILE treatment. The lack of investigation on the effects of higher doses or repeated doses of the antidote treatment and the lack of measurement of drug concentrations at the tissue level, rather than at the serum level, which has not been correlated with the clinical signs of intoxication, are additional limitations of this study.

Cardiovascular toxicity classically manifests as ventricular dysrhythmias, hypotension, heart block, bradyarrhythmias, or asystole. Cardiotoxicity is the primary cause of death associated with TCA poisoning. Hypotension and cardiovascular collapse are primarily caused by ventricular arrhythmias and reduced myocardial contractility, secondary to sodium channel blockage. Sodium channel blockade prolongs the cardiac action potential and the refractory period, and delays atrioventricular node conduction, prolonging the QRS, QTc, and PR durations, respectively. Clinically, QRS prolongation on ECG may potentially be related to increased risks of cardiac arrhythmia and seizures [14].

Many treatment options have been explored to reverse these effects of TCA intoxication; some observational studies and case reports have indicated that only $\mathrm{NaHCO}_{3}$ administration, which maintains a $\mathrm{pH}$ value between 7.45 and 7.55 , has been effective for the rapid correction of hypotension and cardiac arrhythmias, the termination of ventricular arrhythmias, and the reversal of QRS alterations; however, randomized, controlled studies have not been performed. These effects are thought to result from both sodium loading and the positive effects of alkalization [1517]. However, the results of our study are not consistent with those of previous studies, as our study showed that $\mathrm{NaHCO}_{3}$ treatment did not shorten the QRS duration or result in significant MAP elevation.

In experimental TCA intoxication model studies, hypotension is the criterion used to indicate the establishment of intoxication in model subjects. Systolic blood pressure has been used to assess hypotension in some studies, whereas MAP was used in others. A reduction of $50 \%$, relative to baseline values, within $30 \mathrm{~min}$ following clomipramine administration via the oral or IV routes has been accepted as a positive indicator of intoxication in some studies [7, 18, 19].

ECG changes, such as QRS prolongation, enlargement of the PR and QT intervals, and arrhythmias, are important for the diagnosis and follow-up of TCA intoxication. The likelihood that complications will develop is high in the presence of prolonged QRS ( $>100 \mathrm{~ms}$ ) and poor levels of consciousness (Glasgow Coma Scale $<8$ ). Although, TCA toxicity was found to be more likely if plasma levels were $>1,000 \mu \mathrm{g} / \mathrm{L}$, plasma drug levels $<1,000 \mu \mathrm{g} / \mathrm{L}$ have also been associated with toxicity and death. TCA plasma levels had no effects on cardiac and neurological damage followup or the course of treatment [5, 20,21]. In the present study, clomipramine levels changed significantly over time in all groups. Although the clomipramine level increased consistently over time in the $\mathrm{NaHCO}_{3}$ treatment group, the levels began to fall at the end of the first hour in the ILE and glucagon treatment groups (Fig. 2). These differences in clomipramine levels may be due to differences in the 
physiological mechanisms, such as different amounts of drug being absorbed from the gastrointestinal tract, due to different intoxication times among the subjects, alterations in $\mathrm{pH}$ values, changing the proportions of bound and free drug fractions, and changes in the amount of drug that enters the enterohepatic cycle, due to changes in gastric motility [3]. Therefore, serum levels of clomipramine may not represent a sufficiently sensitive or accurate parameter for the evaluation of intoxication and its consequences.

Despite limited clinical evidence, ILE has been recommended as a promising treatment for refractory hemodynamic instability associated with the severe toxicities induced by lipophilic drugs. The original indication for ILE use was systemic toxicity due to local anesthetic complications. ILE treatment is used to treat verapamil, metoprolol, and TCA overdose. However, no consensus currently exists regarding the use of ILE for TCA intoxication because most literature describes case reports, rather than large case series. In experimental TCA intoxication studies, clomipramine-induced hypotension was found to recover faster and more completely following ILE infusions compared with $\mathrm{NaHCO}_{3}$ treatments. In addition, ILE treatment is recommended to be delivered as bolus infusions, in repeated doses. ILE has been placed in the advanced life support guidelines established in 2015 by the American Heart Association (AHA) because it has been used as a life-saving treatment for many intoxication conditions. According to the AHA guideline, ILE has been reported to be accepted for use, together with the standard resuscitation treatment, in patients who experience neurotoxicity or cardiac arrest associated with the systemic toxicity of local anesthetics and other drug toxicities [22-24]. However, no significant differences were observed between the ILE and $\mathrm{NaHCO}_{3}$ treatment groups with regard to the MAP and QRS variables, in this study. In the present study, ILE treatment was not found to be more effective than glucagon treatment for reversing cardiovascular depression (Fig. 1). These results are not consistent with those of previous studies, which indicated the use of lipid emulsions as antidote treatments for lipid-soluble drug intoxication.

Glucagon, administered via the IV route at a dose of 10 mg, should be considered to treat life-threatening hypotension or arrhythmias that are irresponsive to other treatments. Blood pressure was observed to increase and QRS was shortened with the combined use of $\mathrm{NaHCO}_{3}$ and glucagon in a patient with TCA overdose [5].

Evidence supporting routine glucagon use in TCA overdose is limited. Multiple interventions have attempted to discriminate the effects of glucagon reported by case reports $[5,25,26]$. However, no positive effects of glucagon on hypotension or arrhythmia have been determined in experimentally induced TCA intoxication [27]. In the present study, although significant changes in MAP occurred in the glucagon treatment group, no differences were determined in the ILE and $\mathrm{NaHCO}_{3}$ treatment groups.

Although $\mathrm{NaHCO}_{3}$ treatment has been shown to have positive effects on arrhythmia and seizures during TCA intoxication that lead to severe cardiotoxicity, no effect has been reported for QRS [18, 28]. In this study, the rhythm was monitored by ECG at 0, 30, 60, and 120 minutes, in all groups. Although QRS values increased significantly in the sham group, no significant differences were observed in the other treatment groups.

High doses of TCA can lead to respiratory acidosis, resulting in respiratory depression. $\mathrm{NaHCO}_{3}$ treatment has been recommended for many years because toxicityrelated acidosis increases the risks of myocardial depression, arrhythmia, and seizure. During acidosis, the amount of protein-bound TCA increases, whereas the amount of free TCA decreases, which can result in a vicious cycle that worsens respiratory depression [7, 29]. In the present study, although $\mathrm{pH}$ values changed significantly in the ILE and $\mathrm{NaHCO}_{3}$ treatment groups, no significant change was observed in the glucagon treatment group. No significant changes were observed in the $\mathrm{HCO}_{3}$ values for any of the groups (Table 1).

When all clinical results and biochemical markers were evaluated, promising outcomes indicated that glucagon could be used as an antidote, which can reduce toxic cardiac and neurological effects associated with TCA intoxication. As observed in our study, glucagon infusion eliminated cardiotoxic effects by binding free clomipramine, with positive effects many vital parameters (Fig. 1). However, our study was experimental and should be validated by performing larger studies. In addition, given the positive effects of $\mathrm{NaHCO}_{3}$ and ILE treatment, the investigation of the combined effects of glucagon and $\mathrm{NaHCO}_{3}$ treatment could result in more favorable outcomes.

In conclusion, glucagon infusion treatment resulted in better hemodynamic improvements compared with ILE and $\mathrm{NaHCO}_{3}$ treatments for the prevention of clomipraminerelated hypotension, in an experimental model. Although this finding does not provide precise or generalizable evidence, glucagon treatment should be investigated further in future studies, to guide the clinical recommendations for the management of oral lipophilic agent intoxication, such as TCAs. Glucagon should be considered as a potential rescue treatment for severe clomipramine intoxication associated with hemodynamic instability, followed by treatment with $\mathrm{NaHCO}_{3}$, lidocaine, magnesium sulfate, and vasopressors.

\section{ACKNOWLEDGMENTS}

Thank numerous individuals participated in this study.

\section{CONFLICT OF INTEREST}

The authors report no conflicts of interest in this work.

\section{FINANCIAL SUPPORT}

This study was supported by Selçuk Üniversitesi Bilimsel Araştırma Projeleri Koordinatörlüğü. 


\section{REFERENCES}

[1] Liebelt EL. Cyclic antidepressants. In: Goldfrank's Toxicologic Emergencies. 10th edition. Hoffman RS, Howland M, Lewin NA, Nelson LS, Goldfrank LR, editors. United States: McGraw-Hill. 2015;pp:972-982

[2] Wilson, M, Tripp J. Clomipramine. In: StatPearls [Internet]. Treasure Island, FL: StatPearls Publishing; 2020. Available at: https:// www.ncbi.nlm.nih.gov/books/NBK541006/. Accessed March 25,2020

[3] Tay E, Sotiriou A, Graham GG, Wilhelm K, Snowden L, Day RO. Restarting antidepressant and antipsychotic medication after intentional overdoses: need for evidence-based guidance. Ther Adv Psychopharmacol. 2019;9:2045125319836889.

[4] Nelson LS, Erdman AR, Booze LL, Cobaugh DJ, Chyka PA, Woolf $\mathrm{AD}$, et al. Selective serotonin reuptake inhibitor poisoning: An evidence-based consensus guideline for out-of-hospital management. Clin Toxicol (Phila). 2007;45:315-32.

[5] Body R, Bartram T, Azam F, Mackway-Jones K. Guidelines in Emergency Medicine Network (GEMNet): guideline for the management of tricyclic antidepressant overdose. Emerg Med J. 2011;28:347-68.

[6] Chan CY, Waring WS. Images in cardiovascular medicine. Tricyclic cardiotoxicity treated with sodium bicarbonate. Circulation. 2007;115:63-64.

[7] Kerr GW, McGuffie AC, Wilkie S. Tricyclic antidepressant overdose: a review. Emerg Med J. 2001;18:236.

[8] Ferraiolo A, Bordone C, Ramone A, et al. Universal versus risk factor screening for gestational diabetes mellitus. Clinical and experimental obstetrics \& gynecology, 2018;45:53-57.

[9] Rombach SM, Wesselink EJ, de Stoppelaar EI, Rijnsburger ER, Slagt C. Glucagon in hemodynamic instability after tricyclic antidepressant overdose. Netherlands Journal of Critical Care. 2016;24:25-27.

[10] Perichon D, Turfus S, Gerostamoulos D, Graudins A. An assessment of the in vivo effects of intravenous lipid emulsion on blood drug concentration and haemodynamics following oro-gastric amitriptyline overdose. Clin Toxicol (Phila). 2013;51:208-15.

[11] Mottram AR, Bryant SM, Aks SE. Dose-dependent response to cyclodextrin infusion in a rat model of verapamil toxicity. West $\mathrm{J}$ Emerg Med. 2012;13:63-7.

[12] R Core Team (2019). R: A language and environment for statistical computing. R Foundation for Statistical Computing, Vienna, Austria. URL https : //www.R-project.org/.

[13] Benjamini Y, Hochberg Y. Controlling the false discovery rate: a practical and powerful approach to multiple testing. Journal of the Royal Statistical Society Series B, 1995;57:289-300. http://www. jstor.org/stable/2346101.

[14] Thanacoody HK, Thomas SH. Tricyclic antidepressant poisoning :cardiovascular toxicity. Toxicol Rev. 2005;24:205-14.

[15] Vrijlandt PJ, Bosch TM, Zijlstra JG, Tulleken JE, Ligtenberg JJ, van der Werf TS. Sodium bicarbonate infusion for intoxication with tricyclic antidepressives: recommended in spite of lack of scientific evidence. Ned Tijdschrift Geneesk. 2001;145:1686-99.
[16] Kaplan YC, Hocaoglu N, Oransay K, Kalkan S, Tuncok Y. Effect of glucagon on amitriptyline-induced cardiovascular toxicity in rats. Hum Exp Toxicol. 2008;27:321-5.

[17] Eyer F, Stenzel J, Schuster T, Felgenhauer N, Pfab R, von Bary C, et al. Risk assessment of severe tricyclic antidepressant overdose. Hum Exp Toxicol. 2009;28:511-19.

[18] Harvey M, Cave G. Intralipid outperforms sodium bicarbonate in a rabbit model of clomipramine toxicity. Ann Emerg Med. 2007;49:178-85.

[19] Cave G, Harvey M, Shaw T, Damitz R, Chauhan A. Comparison of intravenous lipid emulsion, bicarbonate, and tailored liposomes in rabbit clomipramine toxicity. Acad Emerg Med. 2013;20:1076-9.

[20] Paksu S, Duran L, Altuntas M, Zengin H, Salis O, Ozsevik $\mathrm{S}$, et al. Amitriptyline overdose in emergency department of university hospital: Evaluation of 250 patients. Hum Exp Toxicol. 2014;33(9):980-90.

[21] Power BM, Hackett LP, Dusci LJ, Ilett KF. Antidepressant Toxicity and the Need for Identification and Concentration Monitoring in Overdose. Clin Pharmacokinet. 1995;29:154-71.

[22] Lavonas EJ, Drennan IR, Gabrielli A, Heffner AC, Hoyte CO, Orkin AM, et al. Part 10: Special Circumstances of Resuscitation: 2015 American Heart Association Guidelines Update for Cardiopulmonary Resuscitation and Emergency Cardiovascular Care. Circulation. 2015;132:501-18.

[23] Jamaty C, Bailey B, Larocque A, Notebaert E, Sanogo K, Chauny JM. Lipid emulsions in the treatment of acute poisoning: a systematic review of human and animal studies.Clin Toxicol (Phila). 2010;48:127.

[24] Weinberg GL. Lipid emulsion infusion: resuscitation for local anesthetic and other drug overdose. Anesthesiology. 2012;117:1807.

[25] Sensky PR, Olczak SA. High dose intravenous glucagon in severe tricyclic poisoning. Postgrad Med J. 1999;75:611-2.

[26] Teece S, Hogg K. Glucagon in tricyclic overdose. Emerg Med J. 2003;20:264-5.

[27] Brown TCK. Tricyclic antidepressant overdosage: experimental studies on the management of circulatory complications. Clin Toxicol. 1976;9:255-72.

[28] McCabe JL, Cobaugh DJ, Menegazzi JJ, Fata J. Experimental tricyclic antidepressant toxicity: a randomized, controlled comparison of hypertonic saline solution, sodium bicarbonate, and hyperventilation. Ann Emerg Med. 1998;32:329-33.

[29] Bruccoleri RE, Burns MM. A Literature Review of the Use of Sodium Bicarbonate for the Treatment of QRS Widening. J Med Toxicol. 2016;12:121-9

How to cite this article: HasanKara, AyşegülBayir, AhmetAk, AliÜnlü, SeyitAliKayis. Comparison of Intravenous Lipid Emulsion,Bicarbonate, and Glucagon Treatments in a Rabbit Model of Clomipramine Toxicity. Signa Vitae. 2020;16(2):37-43. doi:10.22514/sv.2020.16.0033. 